Down Syndrome Research and Practice Vol. 5, No. 3, pp 111 - 116

(C) The Down Syndrome Educational Trust

Printed in Great Britain. All Rights Reserved.

ISSN: 0968-7912 (1998) 5:3

\title{
DENTAL CARE FOR THE PATIENT WITH DOWN SYNDROME*
}

\author{
Elizabeth S. Pilcher \\ Medical University of South Carolina
}

\begin{abstract}
This study consists of a clinical and literature review of the special dental considerations unique to individuals with Down syndrome. The author is both a dentist and a parent of a child with Down syndrome. Physical and orofacial characteristics of Down syndrome are discussed including the teeth, gingiva, tongue, palate, and occlusion. Incidences of dental decay and periodontal disease are discussed and how best to treat these diseases in persons with Down syndrome. Most if not all persons with Down syndrome have some type of occlusal disharmony. Techniques to help prevent occlusal problems are discussed, including orthodontic therapy.

Medical problems associated with Down syndrome that can affect dental treatment are discussed. Also, social and emotional factors involved in dental treatment are covered, including techniques to help children with Down syndrome become co-operative dental patients. Information on how to choose the right dentist for your child and how to communicate effectively with the dental staff is given. Finally, information on proper home care and prevention of dental disease is covered, including information on the most recent dental products.
\end{abstract}

Keywords: Down syndrome, dental care, dental treatment

\section{* From a paper presented at the 6th World Congress on Down Syndrome, Madrid, Spain, October 1997.}

\section{Introduction}

Approximately one out of every 800-1,100 births results in an extra chromosome of the twenty first group called Trisomy 21, or Down syndrome. Affecting over 250, 000 people in the U.S. alone, this population has progressed tremendously over recent years to be able to function in the mainstream of society. Inclusive school, work and community settings are now becoming the norm for persons with Down syndrome. This has resulted in a higher level of functioning for most of these individuals with resulting increases in selfesteem and self-image. The demand for dental care in persons with Down syndrome is increasing with this inclusive trend. Most dental treatment for persons with Down syndrome can take place in a general dental office with relatively minor adaptations. In undergraduate dental training there is usually little or no exposure to treating patients with disabilities, and general practitioners may be hesitant to treat these patients with confidence. This paper will attempt to summarise the unique characteristics associated with Down syndrome that influence the dental care and treatment of this population.

Systemic factors influencing dental care Although 40 to $50 \%$ of babies with Down syndrome are born with some type of cardiac abnormality, most receive surgical correction within the first few years of life. There is however, an abnormally large percentage who develop mitral valve prolapse (MVP) by adulthood. The incidence of MVP in the normal population is between 5$15 \%$. Approximately $50 \%$ of adults with Down syndrome have mitral valve prolapse requiring 
subacute bacterial endoconditis (SBE) prophylaxis for dental treatment (Barnett, Friedman, \& Kastner, 1988). One third of these adults with MVP do not have ausculitory findings, requiring diagnosis of the MVP by echocardiogram. Patients with Down syndrome, or their caregivers may not be aware of the need for diagnostic echocardiology in adulthood.

A compromised immune system with a corresponding decrease in number of T cells is characteristic of most individuals with Down syndrome This contributes to a higher rate of infections and is also a contributing factor in the extremely high incidence of periodontal disease. Children with Down syndrome often have chronic upper respiratory infections (URI's). These contribute to mouth breathing with its associated effects of xerostomia (dry mouth) and fissuring of the tongue and lips. There is also a greater incidence of apthous ulcers, oral candida infections and ANUG.

A reduced degree of muscle tone (hypotonia) is generally found in Down syndrome. This affects the musculature of the head and oral cavity as well as the large skeletal muscles. The reduced muscle tone in the lips and cheeks contribute to an imbalance of forces on the teeth with the force of the tongue being a greater influence. This contributes to the open bite often seen in Down syndrome. Additionally, reduced muscle tone causes less efficient chewing and natural cleansing of the teeth. More food may remain on the teeth after eating due to this inefficient chewing.

Associated with the low muscle tone seen in Down syndrome is a ligamentous laxity seen throughout the body. This causes hyperflexibility of the joints and it is theorised that the ligaments around teeth may be influenced as well (Southern Assoc. of Institutional Dentists, pg.4, 1994). A condition related to ligamentous laxity is that of Atlanto Axial Instability. The diagnosis and significance of this condition is controversial but is described as an increase in mobility between the $\mathrm{Cl}$ and $\mathrm{C} 2$ cervical vertebrae and may be seen in $10-20 \%$ of individuals with Down syndrome. If a patient has this instability, careful positioning in the dental chair is required to avoid any potential harm to the spinal cord.

Persons with Down syndrome vary widely as to their degree of intellectual impairment. Most have IQ's in the mild to moderate range and are able to be treated in a normal setting. There is often a relatively severe delay in language development. The patient with Down syndrome will probably understand more than their apparent level of verbal skills. The assistance of the patient's family or caregiver will be necessary in conveying to the dentist and staff what level of communication should be used with the patient. It may take a little extra appointment time to explain procedures to the patient with Down syndrome, but once a level of trust is achieved they are likely to be very co-operative patients.

Down syndrome is frequently seen in conjunction with other medical problems. There is a higher incidence of epilepsy, diabetes, leukaemia, hypothyroidism and other conditions. Alzheimer's disease and Down syndrome appear to have a strong connection to one another. The importance of a thorough medical history including a work-up by a physician cannot be over emphasised.

\section{Orofacial features}

The primary skeletal abnormality affecting the orofacial structures in Down syndrome is an underdevelopment or hypoplasia of the midfacial region. The bridge of the nose, bones of the midface and maxilla are relatively smaller in size. In many instances this causes a prognathic Class III occlusal relationship which contributes to an open bite (Vittek, Winik, Winik, Sioris, Tarangelo et al., 1994). Absence or reduction in size of the frontal and maxillary sinuses is common.

The incidence of mouth breathing is very high due to a small nasal airway. The tongue may protrude and appear to be too large. True macroglossia is rare, rather a relative macroglossia is found where the tongue is of normal size but the oral cavity is decreased in size due to the underdevelopment of the mid-face. Upon examination the palate in a person with Down syndrome appears to be narrow with a high vault. In actuality the vault is of normal

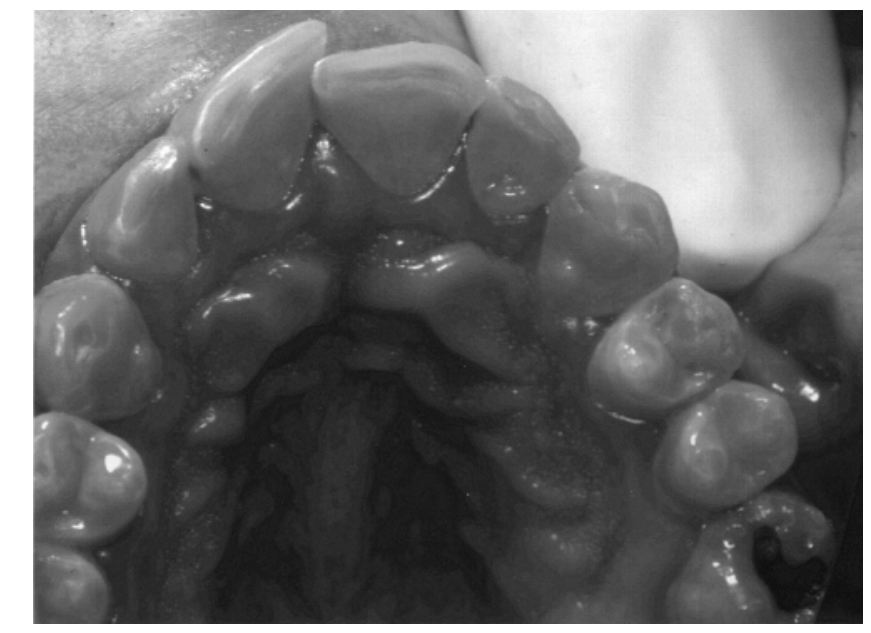


height but the sides of the hard palate are abnormally thick. This creates less space in the oral cavity for the tongue affecting both speech and mastication. Speech pathologists can be of help in teaching correct tongue positioning and increasing the tone of the orofacial musculature. In extreme cases, surgical reduction of the tongue may be indicated (Margar-Bacal, Witzel, \& Munro, 1987; Starmans \& Bloem, 1991).

With age, both the tongue and the lips in people with Down syndrome tend to develop cracks and fissures. This is a result of chronic mouth breathing. Fissuring of the tongue can become severe and be a contributing factor in halitosis. Patients should be instructed to brush their tongue when they brush their teeth. Another result of chronic mouth breathing may be a decrease in saliva with a dry mouth. This reduces the natural cleansing that occurs in the oral cavity and may contribute to the development of caries. Irritation at the corners of the mouth (angular cheilitis) may also be a result of mouth breathing.

The eruption of teeth in persons with Down syndrome is usually delayed and may occur in an unusual order (Mussig, Hickel, \& Zschiesche, 1990; Fisher-Brandeis, 1989). The delay in eruption may be as long as two to three years. Although independence in feeding and the introduction of adult food is encouraged in the toddler with Down syndrome, the diet may need to be altered because not enough teeth have erupted to safely chew some foods. There is an extremely high rate of missing teeth in both the primary and permanent dentitions. Other irregularities such as microdontia and malformed teeth may be seen. However in an oral cavity with undersized bone structure, microdontia and missing teeth may be more of a blessing than a problem. Severe crowding can occur in persons with Down syndrome who have developed all of their permanent dentition (Ondarza, Jara, Bertonati, \& Blanco, 1995). In these cases, selective extractions under the supervision of an orthodontist may be of benefit.

The roots of the teeth in patients with Down syndrome tend to be small and conical. This is an important factor when considering orthodontic tooth movement and also contributes to early tooth loss in periodontal disease.

\section{Dental disease}

Historically the incidence of dental decay in persons with Down syndrome has been reported to be extremely low. Recent studies however have shown that while the incidence is lower, it is not as rare as once thought and it certainly should not be taken for granted that "these patients won't get decay" (Barnett, Press, Friedman, \& Sonnenburg, 1986). Older studies of caries in persons with Down syndrome used institutionalised populations whose diets were controlled. These groups may not have had the exposure to cariogenic foods at the rate of today's children with Down syndrome who are growing up at home. The incidence is lower however, and it is theorised that this may be due to delayed eruption of the teeth, increased spacing between teeth or possible differences in the chemical content of the saliva (Morinushi, Lopatin, \& Tanaka, 1995).

Today, children with Down syndrome should be educated in proper oral hygiene, and receive the benefits of both systemic and topical fluoride. Occlusal sealants are also recommended. Decay in the primary dentition should be promptly treated. With the delayed emergence of the permanent teeth and the high number of missing teeth, it is critical to maintain the primary dentition as long as possible.

On the opposite end of the spectrum from caries is the high rate of periodontal disease seen in Down syndrome (Shapira, Stabholtz, Schurr, Sela, \& Mann, 1991). Early, severe periodontal disease is often seen with onset in the mid to late teen years. Some studies report an incidence of periodontal disease to be between 90 and $96 \%$ in adults with Down syndrome. This is thought to be related to a lowered host response due to the compromised immune system in Down syndrome (Sohoel, Johannessen, Kristofferson, \& Nilsen, 1995; Sohoel, Johannessen, Kristofferson, Haugstvedt, \& Nilsen, 1992; Revland-Bosma, 1990; Shaw \& Saxby, 1986). The amount of plaque and calculus seen on the teeth is not proportionate to the severity of the disease (Yavuzyilmaz, Ersoy, Sanal, Tezcan, \& Ercal, 1993). The teeth most affected are the mandibular incisors and maxillary molars. Good oral hygiene and semi-annual prophylaxis appointments may not be enough to prevent the progression of periodontal disease in these patients. Early, aggressive treatment is needed. These patients may need to be seen as often as every three months for scaling and root planing and may also benefit from the use of chlorhexedine mouth rinse and possibly systemic antibiotic therapy (Stabholtz, Shapira, Shur, Friedman, Guberman, et al., 1991).

Obviously, good home care is essential in the management of periodontal disease of this type. This may be difficult to achieve with the intellectual impairment and decreased manual dexterity seen in Down syndrome. Flossing may be very hard for these patients and instruction in the use of a floss holder may be helpful. New mechanical tooth brushing and flossing aids on the 


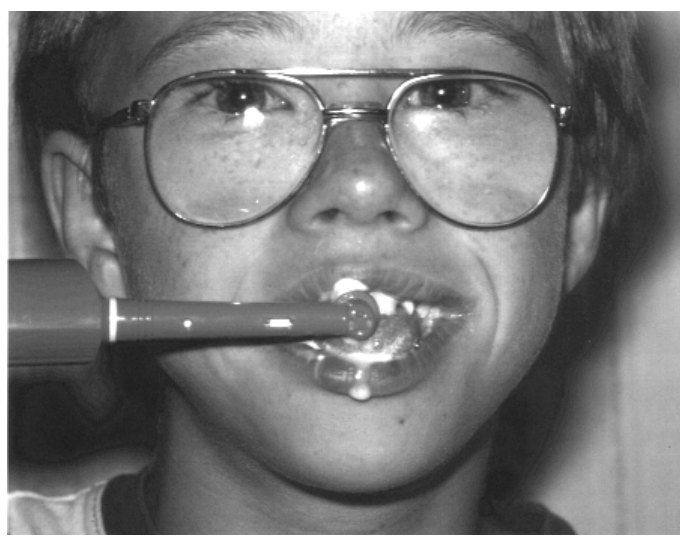

market may also be of help. It is important to be sure that the patient's family or caregiver is educated in proper home care as well. Parents need to realise the importance of proper daily home care because the child with Down syndrome may be resistant to tooth brushing. Additionally, the age at which a child with Down syndrome can be expected to take care of his/her own teeth may be much later than that of normal children.

\section{Treatment objectives}

Treatment objectives for any population with developmental disabilities should be the same as that of normal patients. Treatment plans may need to be adapted as necessary due to each individual's condition, but the overall goal should be to provide as comprehensive treatment as possible. Areas of dental care such as cosmetic dentistry, orthodontics, prosthodontics, and reconstructive oral surgery should not be ruled out simply because the patient has Down syndrome. With the numbers of persons with Down syndrome working and living out in the community, there may be many who desire and can handle some of the more extensive dental treatment options available today.

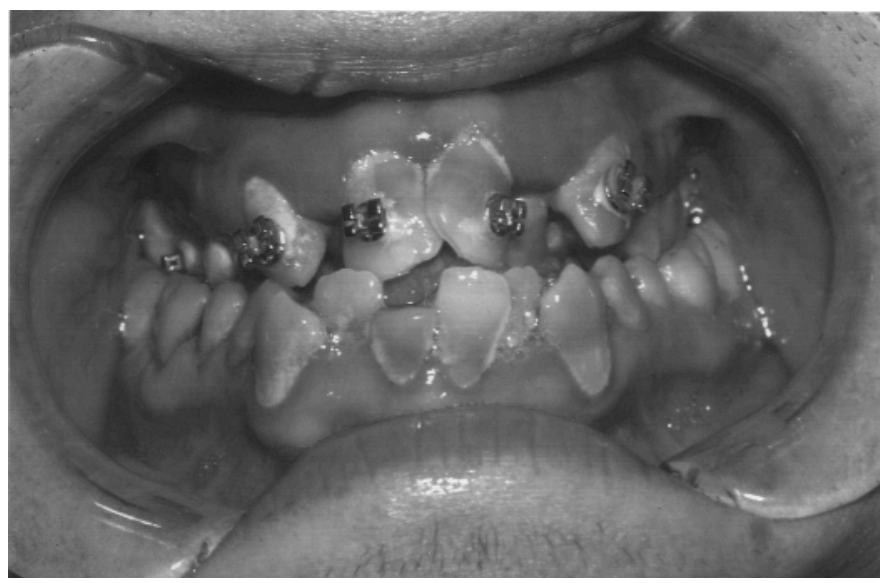

\section{Behaviour management}

Good behaviour in the dental office is learned. In a population with delayed learning, this can be a challenge for the dentist and staff. Dental treatment for children with Down syndrome may not be sought out at an early age. There may be more pressing medical problems, financial considerations or parents may want to wait until the child seems mature enough to handle a visit to the dentist. Unfortunately this makes it more difficult to teach proper home care and to develop a relationship with the child that will result in cooperative behaviour during dental treatment.

Determining the level of communication is very important in developing a co-operative relationship with your patient with Down syndrome. The level of receptive vs. expressive language may not be the same. The patient's family or caregiver will be able to guide the dental staff as to what level of communication is appropriate. It is important that the dentist communicate directly with the patient whenever possible in order to build a level of trust. It may be advantageous to have a parent in the operatory during some early childhood visits. Finding out what motivates the child with Down syndrome is also important. Something as simple as receiving a pair of gloves and a mask at the end of the appointment may be all it takes to ensure co-operation. With more difficult patients requiring more extensive treatment, premedication and/or restraints may be necessary. However, most patients with Down syndrome can handle routine dental care with just a little more time and attention given during the appointment.

Scheduling appointments early in the day is beneficial as both patient and operator are more rested. First appointments should be for orientation only, and subsequent appointments may require a little more time than what is usually allowed. The patient's medical history should be obtained prior to the first appointment. This allows for medical consultation if necessary before any treatment begins.

Treating the older patient with Down syndrome may present a different set of problems. There appears to be a high incidence of early onset Alzheimer's disease in persons with Down syndrome. Studies vary widely, but the incidence has been reported to be anywhere from $30-90 \%$. The average age of onset of clinical symptoms is between 40-50 years (Sigal \& Levine, 1993; Vicari \& Caltigirone, 1990; Devenny, Hill, 


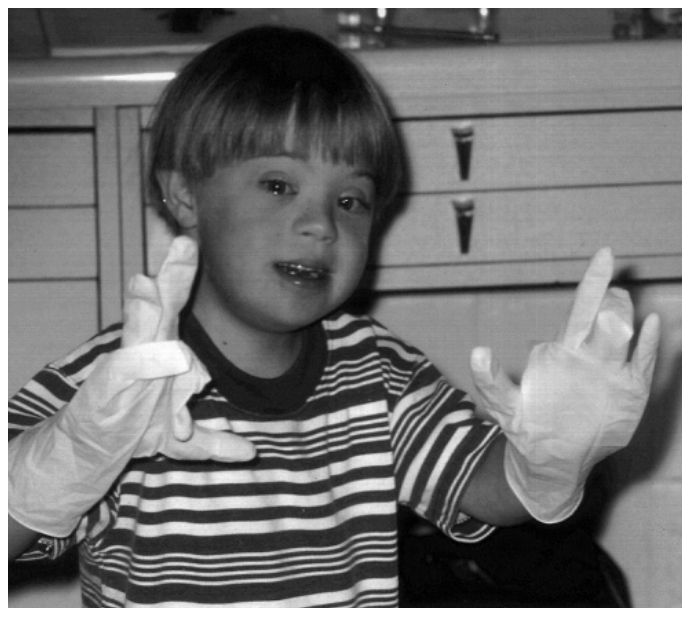

Patxot, Silverman, \& Wisniewski, 1992). These patients will require a great deal of understanding and their level of co-operation may decrease as the disease progresses.

\section{Sleep apnea}

It is important that the dental health provider be aware of the incidence of sleep apnea in the Down syndrome population. It has been reported that the incidence of upper airway obstruction may be as high as $31 \%$ in children with Down syndrome (Stebbens, Dennis, Samuels, Croft, \& Southhall. 1991). The decreased airway size combined with lowered muscle tone predisposes these patients to obstructive sleep apnea. Left untreated, obstructive sleep apnea can further increase developmental delay and lead to pulmonary hypotension and congestive heart failure. Symptoms of obstructive sleep apnea include snoring, restless sleep and unusual sleeping positions. If a patient's family or caregiver reports these symptoms, then referral to a sleep disorders clinic is indicated. Treatment ranges from occlusal repositioning appliances, positive airway pressure and/or surgical correction. Adenotonsillectomy in children with Down syndrome and sleep apnea has been helpful in some cases (Bloch, Witztum, Wieser, Schmid, \& Russi, 1990; Phillips \& Rogers, 1988; Silverman, 1988).

\section{Summary}

Dental care for the patient with Down syndrome can be achieved in the general practitioner's office in most instances with minor adaptations.

Although this population has some unique dental care needs, few patients require special facilities in order to receive dental treatment. Adequate dental health care for persons with developmental disabilities is a major unmet health need. It is hoped that the information contained in this review will encourage general practitioners to be willing to provide comprehensive dental care to their patients with Down syndrome.

\section{Correspondence:}

Elizabeth S. Pilcher, Associate Professor, Department of Prosthodontics, College of Dental Medicine, Medical University of South Carolina, 171 Ashley Avenue, Charleston, South Carolina 29425, U.S.A. (Tel: 803-792-2341, Fax: 803-792159, E-mail: pilchees@musc.edu) 


\section{References}

Barnett, M.L., Friedman D., \& Kastner T. (1988). The prevalence of mitral valve prolapse in patients with Down syndrome: Implications for dental management. Oral Surgery Oral Medicine Oral Pathology, 66, 445-7.

Barnett, M.L., Press, K.P., Friedman, D., \& Sonnenburg E.M. (1986). The prevalence of periodontitis and dental caries in a Down's syndrome population. Journal of Periodontology, 57, 288-93.

Bloch, K., Witztum, A., Wieser, H.G., Schmid, S., \& Russi, E. (1990). Obstructive sleep apnea syndrome in a child with Trisomy 21. Monatsschr ift Kinderheilkunde, 138, 817-22.

Devenny, D.A., Hill, A.L., Patxot, O., Silverman, W.P., \& Wisniewski, K.E. (1992). Ageing in higher functioning adults with Down's syndrome: an interim report in a longitudinal study. Journal of Intellectual Disabilities Research, 36, 24150 .

Fischer-Brandeis, H. (1989). The time of eruption of the milk teeth in Down's syndrome. Fortschritte derKeiferothopadie, 50, 144-51.

Margar-Bacal, F., Witzel, M.A., \& Munro, I.R. (1987). Speech intelligibility after partial glossectomy in children with Down's syndrome. Plastic and Reconstructive Surgery, 79, 44-9.

Morinushi, T., Lopatin, D.E., \& Tanaka, H. (1995). The relationship between dental caries in the primary dentition and anti S. mutans serum antibodies in children with Down's syndrome. Journal of Clinical Pediatric Dentistry, 19, 27983.

Mussig, D., Hickel, R., \& Zschiesche, S. (1990). The eruption of decidious teeth in children with various forms of Down's syndrome and congenital heart defects. Deutsche Zahnarzteblatt, 45, 157-9.

Ondarza, A., Jara, L., Bertonati, M.I., \& Blanco, R. (1995) Tooth malalignments in Chilean children with Down's syndrome. Cleft Palate Craniofacial Journal, 32, 188-93.

Phillips, D.E., \& Rogers, J.H. (1988). Down's syndrome with lingual tonsil hypertrophy producing sleep apnea. Journal of Laryngology \& Otolaryngology, 102, 1054-5.

Revland-Bosma, W. (1990). Periodontal disease in Down's syndrome. Ned Jijdscrift voor Tandheelkkunde, 97, 468-71.

Shapira, J., Stabholtz, A., Schurr, D., Sela, M.N., \& Mann, J.(1991). Caries level, Streptococcus mutans counts, salivary $\mathrm{pH}$ and periodontal treatment needs of adult Down syndrome patients. Special Care Dentist, 11, $248-51$.

Shaw, L., \& Saxby, M.S. (1986). Periodontal destruction in Down's syndrome and in juvenile periodontitis; how close a similarity? Journal of Periodontology, 57, 709-713

Sigal, M.J., \& Levine, N. (1993). Down's syndrome and Alzheimer's disease. Journal of the Canadian Dental Association, 59, 823-29.

Silverman, M. (1988). Airway obstruction and sleep disruption in Down's syndrome. British Medical Journal, 296, 1618-9.

Sohoel, P.D., Johannessen, A.C., Kristofferson, T., Haugstvedt, Y., \& Nilsen, R. (1992). In situ characteristics of mononuclear cells in marginal periodontitis of patients with Down syndrome. Acta Odontologica Scandinavica, 50, 141-9.

Sohoel, P.D., Johannessen, A.C., Kristofferson, T., \& Nilsen, R. (1995). Expression of HLA Class II antigens in marginal periodontitis of patient's with Down's syndrome. European Journal of Oral Science, 103, 207-13.

Southern Association of Institutional Dentists (1994). Southern Association of Institutional Dentists Self study course: Module 3 Down Syndrome.

Stabholtz, A., Shapira, J., Shur, D., Friedman, M., Guberman, R., \& Sela, M.N. (1991). Local application of sustained release delivery system of chlorhexedine in Down's syndrome population. Clinical Preventive Dentistry, 13, 9-14.

Starmans, J.L., \& Bloem, J.J.(1991). Tongue reduction in children with Down's syndrome, a functional operation. Nederlands Tijdschrift Voor Geneeskunde, 135, 1963-6.

Stebbens, V.A., Dennis, J., Samuels, M.P., Croft, C.B., \& Southhall, D.P. (1991). Sleep related upper airway obstruction in a cohort with Down's syndrome. Archives of the Disabled Child, 66, 1333-8.

Vicari, S., \& Caltagirone, C.(1990). Alzheimer's disease and Down syndrome: a review. Rivista Neurologia, 60, 151-9.

Vittek, J., Winik, S., Winik, A., Sioris, C., Tarangelo, A.M., \& Chou, M. (1994). Analysis of orthodontic anomalies in mentally retarded developmentally disabled persons. Special Care Dentist, 14, 198-202.

Yavuzyilmaz, E., Ersoy, F., Sanal, O., Tezcan, I., \& Ercal, D. (1993). Neutrophil chemotaxis and periodontal status in Down syndrome patients. Journal of Nihon University School of Dentistry, 35, 91-5. 